\title{
Changeover contingencies and choice on concurrent schedules
}

\author{
LEON R. DREYFUS, DEE DEPORTO-CALLAN, and SARAH ANNA PESILLO \\ Vassar College, Poughkeepsie, New York
}

\begin{abstract}
Pigeons were trained on a multiple concurrent schedule with two components per session. In one component, changing schedules required the completion of a small fixed ratio on the switching key (a fixed-ratio changeover, or FRCO), and in the other component, changing schedules required only one switching response but engaged a changeover delay (COD) during which keypecks were not reinforced. Response ratios overmatched reinforcer ratios under the FRCO but undermatched under the COD. There was no difference in time allocation. In addition to these molar regularities in behavior, there were characteristic differences in performance at the molecular level. These local patterns of behavior, which can be explained within the context of contingencies created by the different changeover requirements, appear to underlie differences in performance at the molar level. Obtained molar differences in performance are not compatible with the assumption that there is a "general outcome" on concurrent schedules; and explaining these molar differences in performance in terms of the local contingencies of reinforcement is contrary to the assumption that behavior is allocated as a function of molar distributions of reinforcers.
\end{abstract}

Much of the data on choice behavior of nonhumans has been generated in the context of relatively few procedures. Perhaps the most common procedure involves the use of concurrent schedules of reinforcement. Data generated under several variations of this procedure can be described well in terms of a generalized version of the matching relation (Davison \& McCarthy, 1988). This matching relation is the current standard against which choice data are compared, as well as a generalization that theories of choice must accommodate. According to the generalized matching relation (Baum, 1974),

$$
B_{1} / B_{2}=b\left(R_{1} / R_{2}\right)^{a},
$$

where $B$ denotes a measure of behavior (responses or time), $R$ denotes the rate of reinforcement, and the subscripts identify two schedules. Taking the logarithm of each side of the equation produces the expression

$$
\log \left(B_{1} / B_{2}\right)=a \log \left(R_{1} / R_{2}\right)+\log b,
$$

a straight line with slope $a$ and intercept $\log b$. The constant $\log b$ is taken as a measure of bias, and the parameter $a$ reflects the degree to which changes in reinforcement ratios are reflected in behavior ratios (see Baum, 1974, 1979 , for more details). Perfect matching is observed when $\log b$ equals zero and $a$ is equal to one. If $a$ is less than unity, behavior ratios undermatch or underestimate rein-

Portions of these data were presented at the meeting of the Psychonomic Society, San Francisco, 1991. The authors acknowledge support by institutional funds under the auspices of the Vassar College Undergraduate Summer Research Institute to L.R.D. and S.A.P. Alan Stubbs, with whom these issues have been discussed many times, made helpful comments on an earlier version of this article. Correspondence should be addressed to L. R. Dreyfus, Department of Psychology, Vassar College, Poughkeepsie, NY 12601 (e-mail: dreyfus@vaxsar.vassar.edu). forcement ratios, and if $a$ is greater than unity, behavior ratios overmatch or overestimate reinforcement ratios.

The most typical finding from the use of concurrent variable interval (VI) schedules is that behavior ratios undermatch reinforcement ratios. These results have prompted several reviewers (Davison \& McCarthy, 1988; Myers \& Myers, 1977; Wearden \& Burgess, 1982) to conclude that undermatching is the "general outcome" on concurrent schedules. In a relatively smaller number of studies, however, behavior ratios that overmatch reinforcement ratios have been reported (Baum, 1982; Dunn, 1982; Pliskoff, Cicerone, \& Nelson, 1978; Pliskoff \& Fetterman, 1981). There is a systematic difference between these and the bulk of concurrent schedule experiments. In most studies reporting undermatching, only a single peck has been required to change schedules, and this peck has usually engaged a changeover delay (COD) - a short period of time following the change from one schedule to another, in which responses can be directed at the manipulandum but are not eligible for reinforcement. By contrast, most reports of overmatching have resulted from the use of a fixed-ratio changeover (FRCO) requirement or something comparable. With a changeover ratio, several pecks on a separate, changeover key alternate the schedule and main-key color.

As changeover requirements, the FRCO and COD establish different changeover contingencies. With a COD, the first peck following a changeover cannot be reinforced unless it is withheld for the duration of the COD. By contrast, the first peck following the completion of an FRCO is eligible for reinforcement. Pliskoff et al. (1978) reported that the contingencies arranged by these changeover requirements fostered different patterns of postchangeover behavior-for example, as local rates of responding im- 
mediately after the changeover differ under COD and FRCO requirements. These authors suggested that such patterns contributed to the observed molar results-that is, undermatching with a COD and overmatching with an FRCO. Dreyfus, Dorman, Fetterman, and Stubbs (1982) demonstrated regularities in the way that reinforcers become available on concurrent interval schedules and proposed that the numbers of reinforcers available immediately after a changeover requirement has been fulfilled could plausibly account for both molar and molecular differences in performance under COD and FRCO requirements. In addition, Pliskoff and Dreyfus (1982) showed further details of the local structure of behavior that were consistent with both the data presented by Pliskoff et al. (1978) and the predictions of Dreyfus et al. (1982).

The question, then, is how we interpret the molar differences in performance that result from the use of different changeover requirements. According to a strictly molar account, behavior allocation varies as a function of the ratio of reinforcers delivered by the two schedules. Although the generalized matching equation can adequately describe the types of performance that accompany a COD and an FRCO (undermatching and overmatching, respectively), it falls short of explaining these different patterns of behavior. In addition, these different outcomes seem to undermine the conclusion that undermatching is the "general outcome," although Taylor and Davison (1983) have offered one way around this difficulty by suggesting that overmatching under the FRCO is an artifact. They demonstrated that the inclusion of changeover responses and time in the computation of behavior ratios preserves undermatching as a "general outcome." There is, however, disagreement over the appropriateness of their resolution of the matter (Baum, 1982). In contrast with an exclusively molar account, the analysis of Dreyfus et al. (1982) suggests that the molar differences in performance that accompany COD and FRCO requirements have more to do with the local patterns of behavior that develop as a result of the interaction of the different changeover requirements with the availability of reinforcers after a changeover. According to this account, the deviations from strict matching under COD and FRCO requirements result from the following differences in performance: (1) under a COD requirement, there is a high rate of responding on both schedules during the $\mathrm{COD}$, produced by a relatively high probability of food at the end of the COD; and (2) under an FRCO, response runs on the schedule providing the lower relative rate of reinforcement are relatively short, since reinforcers on this schedule are often produced by the first postchangeover response. These patterns produce differences in responses allocated to the schedule providing the lower relative rate of reinforcement. Under the COD, response allocation to this schedule is higher than that predicted by relative reinforcement rate, undermatching, whereas under the FRCO, response allocation to this schedule is lower than that predicted by relative reinforcement rate, overmatching.

Our primary purpose in the present experiment was to determine the extent to which the molar patterns of be- havior, undermatching under a COD and overmatching under an FRCO, were accompanied by the systematic molecular changes predicted by Dreyfus et al. (1982)-a high rate of responding during the COD on both schedules and shorter response runs under an FRCO than under a COD on the schedule providing the lower relative rate of reinforcement. Secondarily, in order to control the influence of other variables as well as to determine the robustness of characteristic performance under the COD and FRCO, we sought to determine whether both molar and molecular patterns of performance would obtain when the changeover requirement varied within each session. To address these questions, a concurrent schedule was arranged in which the color of the changeover key signaled whether a COD or an FRCO requirement was in effect. Each requirement was equally likely to appear throughout the first half of a 90 -min session, and the other was in effect in the final half.

\section{METHOD}

\section{Subjects}

Three White Carneau pigeons served. One (B48) was experimentally naive at the outset of this experiment, and the other 2 (B41 and B47) participated over a period of 4 months in laboratory exercises involving a series of autoshaping conditions and a multiple schedule. Participation in the laboratory exercises was completed 8 months prior to the beginning of pretraining for the present experiment. All pigeons were maintained at approximately $85 \%$ of their free-feeding weights and were given unlimited access to water and grit in their home cages. Supplementary food was provided in the home cage as was needed to maintain the specified level of deprivation.

\section{Apparatus}

The experiment was conducted in two sound-insulated, ventilated pigeon chambers with work spaces measuring $32 \mathrm{~cm}$ high $\times 34 \mathrm{~cm}$ wide $\times 33.5 \mathrm{~cm}$ deep. Three keys were accessible through $2-\mathrm{cm}$ circular openings in the work panel, with the center of the openings spaced $6.3 \mathrm{~cm}$ apart and $23 \mathrm{~cm}$ above a wire-mesh floor. A force of approximately $0.15 \mathrm{~N}$ was required to operate the keys. A solenoid-operated grain feeder could be accessed through a 5.5$\mathrm{cm}$-square opening centrally located below the keys; the bottom of this opening was $9 \mathrm{~cm}$ above the floor. Masking noise was provided through a speaker in the chamber. The experimental events were scheduled and recorded by laboratory computers and interfaces in an adjacent room.

\section{Procedure}

Pretraining of the pigeons began with magazine training followed by an autoshaping procedure. Once keypecking was established, the pigeons were exposed to a series of fixed-ratio (FR) schedules and multiple FR FR schedules. On the multiple FR FR schedule, the left key was lit by either a red or a green light, a reinforcer was produced in either color by completing the ratio, and the color was switched following the delivery of each reinforcer. Following the multiple FR FR, the pigeons were switched to a multiple VI VI schedule with an equal rate of reinforcement in alternating red and green components. Initially, there were forty 1-min components per session and a VI 30-sec schedule in effect. This was then changed to a VI 60-sec schedule, and the number of components was increased to 90 per session. The pigeons remained on the latter multiple schedule for approximately 35 sessions. The final stage of pretraining involved a change to a concurrent VI VI schedule. On the concurrent schedule, the left key could be lit by red or green 
light. The center key was lit by white light, and pecks to this key changed the color of the left key and began a 2-sec blackout period during which all lights in the chamber were off, keypecks had no scheduled consequences, and all timing operations-such as the setting up of reinforcers or the accumulation of time under either mainkey color-were halted. Following this blackout, the side key was lit by the alternate color and the center key remained dark and inoperative until at least one peck had been made on the side key.

Overall, reinforcers were made available on a VI 60 -sec schedule and the relative reinforcement rate was varied over a series of conditions. The relative rate in red began at .5 for 19 sessions; it was changed to .25 for 19 sessions, and then to .75 for 28 sessions. All VI schedules were constant-probability schedules (Catania \& Reynolds, 1968) that comprised 20 intervals and were arranged by the computer so that each interval was sampled without replacement from the entire set before any interval was repeated. The order of intervals changed irregularly from one complete set to the next. Once a reinforcer was arranged by the VI schedule, it was assigned probabilistically to one of the main-key colors and no further reinforcers were assigned until it was collected (Stubbs \& Pliskoff, 1969).

The multiple concurrent schedule was identical to the concurrent schedule in many respects. Reinforcers were made available by a VI 60 -sec schedule and assigned to red or green on the basis of the current relative rate of reinforcement. The multiple concurrent schedule was different, however, in that sessions were broken into two distinct periods with different changeover requirements in effect. The sessions lasted $90 \mathrm{~min}$, but, during the first $45 \mathrm{~min}$ of the session, one changeover requirement was in effect, and, during the remainder of the session, the other changeover requirement was in effect. Which changeover requirement was in effect was signaled by the color of the center key. This key was illuminated by blue light when the FRCO was in effect and by amber light when the COD was in effect. Each changeover requirement was equally likely to occur first during each session, and the change of components was accompanied by a 30 -sec blackout in which all lights in the chamber were off, all timing operations were halted, and keypecks had no scheduled consequences.
Under the FRCO, five pecks to the center key were required to change the color of the side key. The first peck to the changeover key darkened the main key. The fifth peck to the changeover key reilluminated the main key with the alternate color and darkened and disabled the changeover key. The first peck to the main key following a changeover reilluminated and enabled the changeover key. Under the COD, a peck to the changeover key produced immediately the alternate color on the main key and darkened and disabled the changeover key. The first peck to the main key reilluminated and enabled the changeover key. Pecks to the main key during the 2 -sec period immediately following a changeover were counted but were not eligible for reinforcement. According to standard procedure with these changeover requirements, timing operations were halted during the FRCO but continued during the COD.

Under the multiple concurrent schedule, the primary manipulation involved changes in relative reinforcement rate. Relative reinforcement rate, computed with respect to red, began at .75 and was shifted to .25 and then to .50 . The pigeons continued on each condition until relative response and time allocation within each component were stable as judged visually from day to day. In addition, conditions were sometimes continued after a point had been reached at which performance was stable, until sufficient data could be accumulated with each changeover requirement in each component of the multiple schedule. The length of exposure to each condition varied from 44 to 60 sessions.

\section{RESULTS}

Figure 1 shows the relations between the ratios of obtained reinforcers and the ratios of responses (top panels) or time (bottom panels) allocated to each schedule of the concurrent pair. Each column shows the performance of 1 pigeon. In each panel, there are separate functions for the different changeover requirements, COD or FRCO, as either the first or the second component of the session.
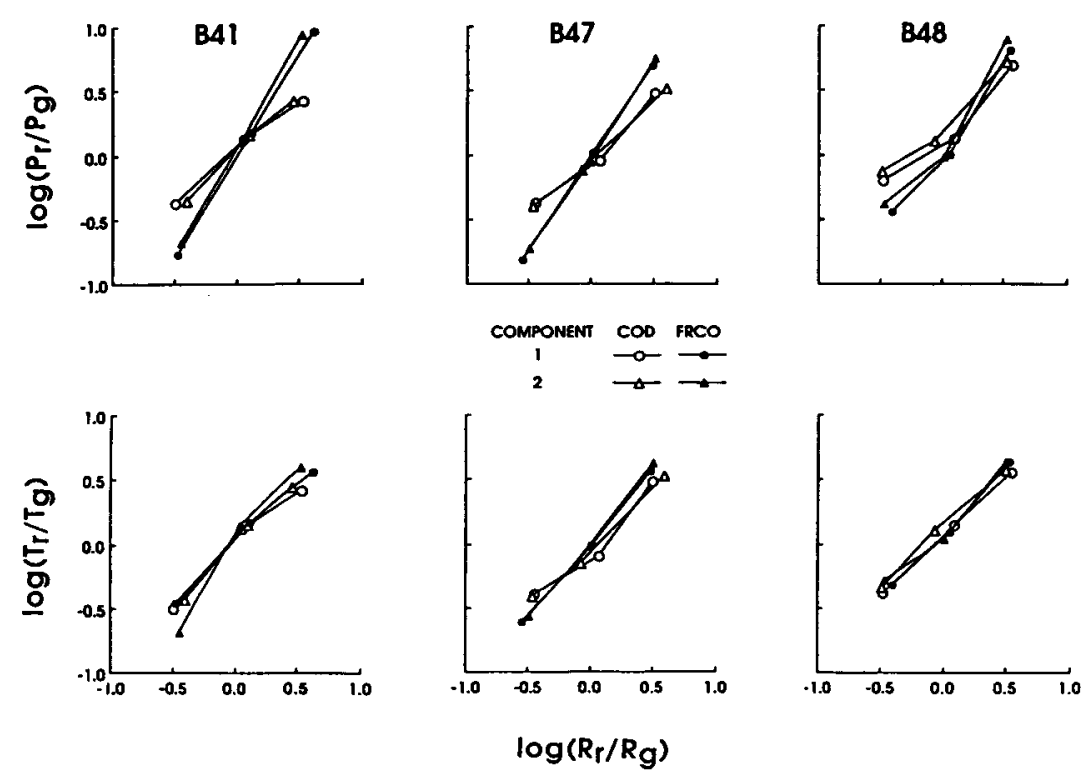

Figure 1. Log ratio of pecks (top panels) or time (bottom panels) allocated to red and green as a function of $\log$ ratio of reinforcers. A separate function is shown in each panel for data accumulated when $\mathrm{COD}$ or FRCO requirements were in effect and when each of these changeover requirements was the first or second component of a session. Pigeon numbers are shown at the top of the upper panels. (These data were accumulated over the final 14-19 sessions of each condition.) 
Figure 1 shows that the response functions are steeper for the FRCO than for the COD. Second, it shows that there is little difference between time functions under FRCO or COD requirements. Finally, it shows that, within each panel, there were no differences in the slopes of the response functions or in the slopes of the time functions as a result of the component in which a changeover requirement appeared.

Straight lines were fit by the method of least squares to the functions in Figure 1. Figure 2 shows the average slopes and intercepts of those best-fitting lines. Under the linear version of the generalized matching equation (2), perfect matching obtains when the slope, $a$, is equal to one and the intercept, $\log b$, is equal to zero-that is, when
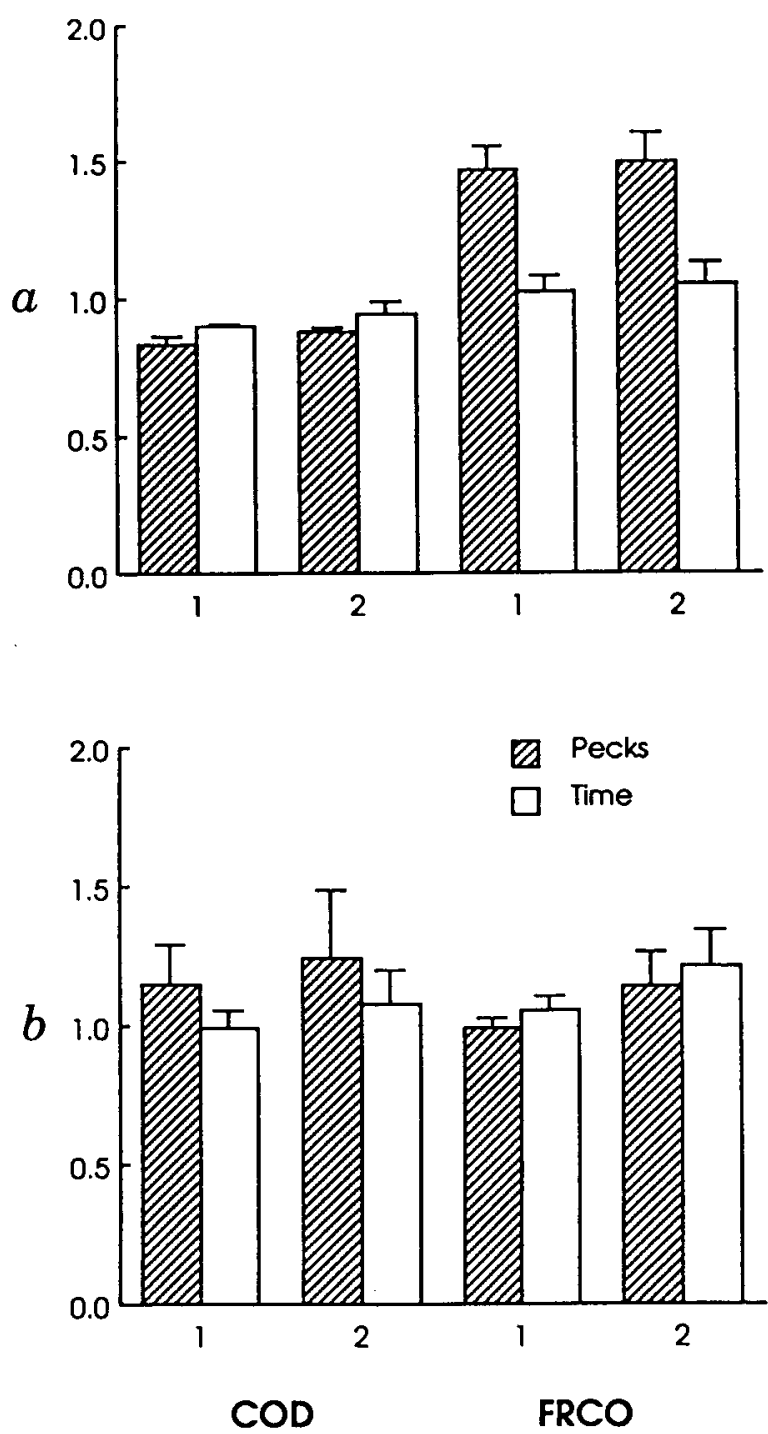

Figure 2. Average slopes, $a$, and intercepts, $b$, of best fits of the linear version of the generalized matching equation to the functions shown in Figure 1. Under both COD and FRCO requirements, separate parameter values are shown for response and time functions and for data accumulated over the first or second component of a session. (Bars represent standard errors of the means.) $b$ is equal to one. Average parameter values are shown for response and time measures under the COD and FRCO and as the first and second compronents of sessions. The top panel shows that the slope of the response functions depended on the changeover requirement. Under a COD, response ratios undermatched reinforcer ratios, whereas under an FRCO, response ratios overmatched. Under both the COD and the FRCO, the slopes of the functions relating time to reinforcer ratios were closer to 1.0 , and differences in slopes between these conditions were smaller than differences between response slopes. The lower panel shows that intercepts were close to 1.0 across conditions, indicating minimal bias. This panel also indicates that differences in bias under the COD and FRCO, whether for responses or for time, were smaller and less systematic than the differences in the slopes of response functions. Finally, each changeover requirement produced a similar slope and bias whether it occurred in the first or second component of a session.

The data shown in Figure 2 were analyzed further with two-way (changeover requirement $\times$ component), withinsubject analyses of variance (ANOVAs). Four analyses were conducted: Separate analyses of slope and bias parameters were completed for the time and response data. These analyses revealed that slopes of the response functions were significantly higher under the FRCO than under the $\operatorname{COD}[F(1,2)=42.77, p<.05]$, but there was no difference in whether slopes were calculated during the first or second half of a session. There were no significant differences in slopes for the time measure. Bias for the response measure did not differ significantly by changeover requirement or by component. Bias for the time measure was significantly higher under the FRCO than under the $\operatorname{COD}[F(1,2)=28.92, p<.05]$, but did not vary as a function of the component in which it was calculated.

Local patterns of behavior that accompanied the different changeover requirements are presented in Figures 3 and 4 . Figure 3 shows the average run length and average bout time on a schedule before the change to the alternate schedule, as they varied with relative reinforcement rate. The average run length and bout time were calculated by dividing the number of responses emitted and the amount of time allocated to each schedule during each session by the number of exposures to the schedule in that session. These averages were averaged over approximately the last 16 sessions of each condition (the sessions represented in Figures 1 and 2). Finally, run lengths and bout times for red and green under identical programmed relative reinforcement rates were averaged.

The average run length data shown in the top panels suggest several generalizations. First, run length increases as a function of relative reinforcement rate. Second, run length appears different for different changeover requirements. For 2 of the 3 pigeons, run lengths appear lower with an FRCO requirement, and for all 3 pigeons, run length at the lowest relative reinforcement rate appears lower under the FRCO. Third, there is no apparent difference in run lengths as a function of whether they were 

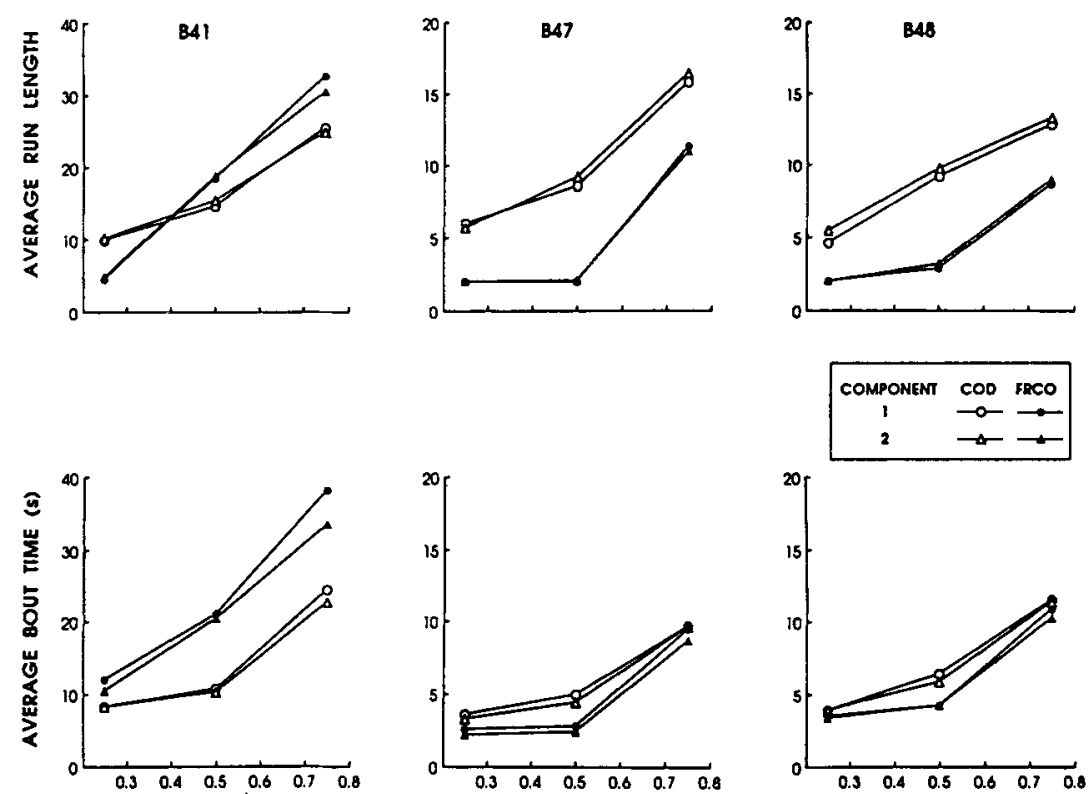

RELATVE REINFORCEMENT RATE

Figure 3. Average run length and bout duration under COD and FRCO requirements for each pigeon as a function of programmed relative reinforcement rate. (Each point is the average over the sessions summarized in Figure 1. Note different ranges for the ordinate.)
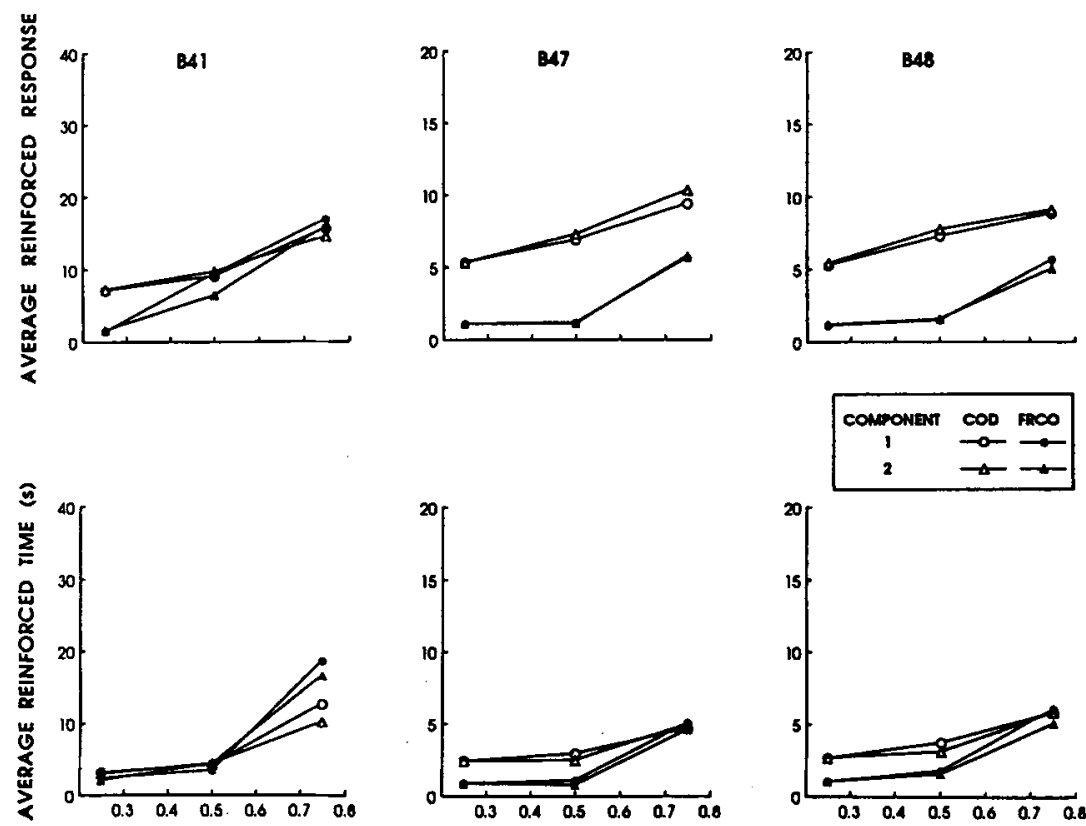

RELATIVE REINFORCEMENT RATE

Figure 4. Average reinforced response and reinforced time under $\mathrm{COD}$ and FRCO requirements for each pigeon as a function of programmed relative reinforcement rate. (Each point is the average over the sessions summarized in Figure 1. Note different ranges for the ordinate.) 
calculated from the first or the second half of the session. The average bout time data are shown in the lower panels. Bout time increases with relative reinforcement rate. The effects of changeover requirement are less clear. Bout time for 1 pigeon appears longer under the FRCO, whereas, for the other 2 pigeons, bout times are more similar under the COD and FRCO with a slight indication that when relative reinforcement rates are equal, they are longer under the COD. Finally, as with the run length data, there is no consistent difference in bout times that depends on the component in which they were calculated.

Average run length and bout time data were evaluated with two three-way ANOVAs (changeover requirement $x$ relative reinforcement rate $x$ component). The analysis of run length data showed a significant increase in run length with relative reinforcement rate $[F(2,4)=8.93$, $p<.05]$. In addition, changeover requirement interacted with component number $[F(1,2)=40.69, p<.05]$. Further analyses of the changeover requirement $\times$ component interaction showed that none of the individual comparisons was significant. There were no other significant effects. The failure to find differences in run length with changeover requirement is contrary to expectations set forth in the introduction. However, our prediction was that run length would differ under the COD and FRCO only for the schedule providing the lower relative rate of reinforcement. That difference is consistent in Figure 3. On the strength of the apparent difference in the figure and the hypothesized difference at this level of relative reinforcement rate, we undertook a statistical comparison of run length under the COD and FRCO at the lower relative rate of reinforcement. Run lengths shown in Figure 3 were averaged over first and second components and compared in a paired $t$ test. The results of the test showed that run lengths at a relative reinforcement rate of .25 were shorter under the FRCO than under the COD $[t(2)=$ $4.07, p<.05]$.

The ANOVA for bout time showed that it increased with relative reinforcement rate $[F(2,4)=7.16, p<$ $.05]$. The only other significant effect of this analysis was a significant interaction of changeover requirement, relative reinforcement rate, and component $[F(2,4)=7.17$, $p<.05]$. Examination of the relevant means suggested that this interaction was produced by a difference under the COD and FRCO in the way that bout time at the highest relative rate of reinforcement changed over components.

Figure 4 shows the average reinforced response (the response within the bout that produced a reinforcer) and the average reinforced time (the time into the bout at which a reinforcer was produced), as they varied with relative reinforcement rate. Average reinforced response and average reinforced time were computed in the following way. Each time a reinforcer was delivered, the number since the prior changeover of the response that produced the reinforcer and the amount of time since the prior changeover were recorded (timing from the point at which the main key was illuminated). At the end of each session, these response numbers and times were sunimed over the session, with separate totals for each main-key color. Ses- sion averages were computed by dividing the respective sums by the number of reinforcers produced in each color. These session averages were averaged over the last 16 sessions of each condition (the same sessions represented in Figures 1 and 2). Finally, as with average run length and average bout time, average reinforced response and average reinforced time for red and green under identical programmed relative reinforcement rates were averaged.

The pattern in the average reinforced response data was very similar to that of the average run length data shown in Figure 3. Average reinforced response increased with relative reinforcement rate, but the increase was not as large as that for average run length. For 2 pigeons, reinforced run length under the FRCO was uniformly shorter than under the COD, and for the other, it was shorter only at the lowest relative reinforcement rate. Finally, average reinforced response did not appear to differ as a function of the component from which it was calculated. The average reinforced bout times, shown in the bottom panels, were similar to the bout time data shown in Figure 3. Average reinforced bout time increased with increases in relative reinforcement rate. Differences in average reinforced bout times under COD and FRCO were unsystematic. Where there was a difference in average reinforced bout time that depended on the component in which it was calculated, it appeared slightly longer in the first component.

Differences in average reinforced response and average reinforced bout time were evaluated with separate three-way ANOVAs. The analysis of average reinforced response revealed significant effects of changeover requirement $[F(1,2)=17.4, p<.05]$ and relative reinforcement rate $[F(2,4)=7.71, p<.05]$. There were no other significant effects. The analysis of reinforced bout time produced no significant effects.

Pliskoff et al. (1978) and Silberberg and Fantino (1970) reported rates of responding during the COD higher than those following the COD, and Dreyfus et al. (1982) suggested that the high rate during the COD was responsible in part for the undermatching of responses. In order to determine whether this rate difference was present in the current situation, local response rates (i.e., responses in a color divided by time in that color) during and after the COD were calculated and are shown in the top panels of Figure 5. These data show that rate of responding during the COD was consistently higher than post-COD rates. For comparison, the bottom panels show the rate of responding during the completion of the changeover ratio and the subsequent rate of responding on the main key. These panels show that performance under the FRCO can also be broken down into a high-rate component, on the changeover key during completion of the ratio, and a low-rate component, on the main key after completion of the FRCO.

\section{DISCUSSION}

The present data corroborate earlier findings that response ratios on concurrent schedules undermatch reinforcer ratios with a COD and overmatch reinforcer ra- 

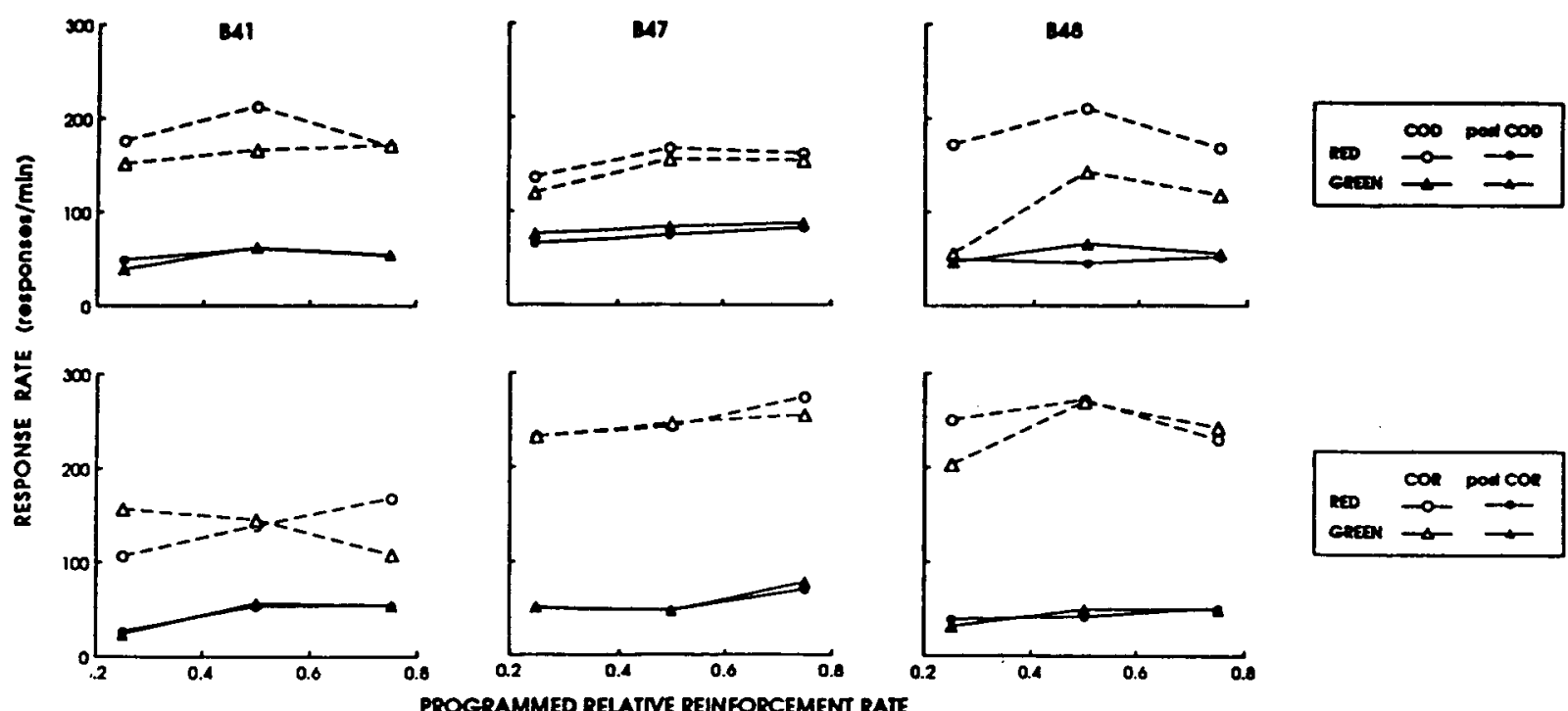

Figure 5. Response rates during and after completion of changeover requirements. Top panels show response rates during and after completion of the COD, and bottom panels show rate of responding during and after completion of changeover ratio. (Each point is the average of daily rates computed for each of the sessions shown in Figure 1.)

tios with an FRCO requirement. These molar patterns of performance are robust in that they are obtained even when the different changeover requirements are scheduled in different parts of the same session. In addition, the present results illustrate in greater detail than that demonstrated by Pliskoff et al. (1978) that these changeover requirements produce different patterns of performance at the molecular level.

These results raise several questions. First, what is the origin of molecular differences in performance under the COD and FRCO? Second, what is the relation of behavior at the molecular level to differences in performance at the molar level? And third, what do these data imply for our understanding of choice on concurrent schedules? These questions will be addressed in turn.

\section{Molecular Differences in Performance}

An understanding of how the different molecular patterns of performance originate follows directly from a consideration of the way in which reinforcers become available on concurrent schedules and of the different contingencies of reinforcement arranged by the COD and FRCO. Reinforcers become available on each schedule of a concurrent pair in one of two ways: they become available while the subject works on the current schedule or while the subject works on the alternate schedule. Reinforcers that become available while working on the alternate schedule can be collected by the first eligible response after a changeover. Dreyfus et al. (1982) showed how the proportion of reinforcers that become available in each way depends on time allocation. For example, if $75 \%$ of available time is allocated to one schedule, $A$, of a pair, $A$ and $B$, then $75 \%$ of the reinforcers delivered by schedule $A$ will become available while the subject works on $A$ and the other $25 \%$ while the subject works on $B$. The reverse is true for schedule $B ; 25 \%$ of schedule $B$ reinforcers will become available while the subject works on $B$, and $75 \%$ will become available while the subject works on $A$. Thus for the schedule of a pair delivering the lower relative rate of reinforcement (i.e., the lean schedule), the proportion of reinforcers available for the first eligible response after the change to that schedule will equal the proportion of time allocated to the richer schedule. The more extreme the time allocation in favor of the richer schedule, the higher the proportion of reinforcers on the lean schedule available immediately after a changeover.

We contend that this characteristic of concurrent schedules, along with the differences in COD and FRCO requirements, generates the molecular patterns of performance observed in this experiment. Under the FRCO, the first main-key response after a changeover is eligible for reinforcement; under a COD, the main key is lit immediately after completion of the changeover response, but mainkey pecks are not reinforced until the delay has expired. This difference in changeover requirements and the high percentage of reinforcers available for the first response following a change to the lean schedule can plausibly account for our finding that run lengths on the lean schedule were shorter under FRCO than under COD. In addition, Figure 4 showed that the average reinforced run lengths and bout times were in close correspondence with the average run length and bout times shown in Figure 3 . This correspondence between emitted and reinforced run lengths, which has been demonstrated previously (see, e.g., Menlove, 1975), does not prove that reinforcement acts locally to produce the observed molecular differences in performance, but such correspondence is a necessary 
condition for such an account. These results complement other demonstrations of local organization in behavior created by local contingencies of reinforcement (see, e.g., Shimp, 1982; Silberberg \& Ziriax, 1982).

\section{Molar and Molecular Effects}

Much of the discussion about choice in general and behavior under concurrent schedules in particular has focused on whether regularities that emerge, such as the matching relation, are the result of a molar or a molecular process (Commons, Herrnstein, \& Rachlin, 1982). The present results, as well as prior research, have shown that $\mathrm{COD}$ and $\mathrm{FRCO}$ as changeover requirements produce different patterns of behavior at both the molar and the molecular level. It is reasonable, therefore, to inquire about the relation between regularities in performance at these two levels.

Dreyfus et al. (1982) suggested that relatively short response runs on the schedule providing the lower relative rate were primarily responsible for overmatching under an FRCO requirement, and that the high rate of responding during the COD was responsible, at least in part, for undermatching under a COD. With regard to the latter suggestion, the top panel of Figure 5 shows that response rates during the COD were higher than post-COD rates. Insofar as responses during the COD contribute to the response totals on each schedule and bout durations and run lengths are shorter on the lean schedule, COD responses contribute a much larger portion of the responses on this schedule and serve to drive response ratios toward indifference. Although this analysis would seem to suggest that longer CODs should produce progressively greater undermatching, studies in which COD duration has been manipulated (e.g., Stubbs \& Pliskoff, 1969) have typically reported that when COD duration increases, relative response and time allocation remain relatively stable. This apparent discrepancy results, however, from several other effects of lengthening the COD. Increasing the duration of the COD reduces the number of changeovers, and increasing the COD beyond a certain point produces a decrease in the rate of responding during the COD (Pliskoff, 1971). The present analysis would predict greater undermatching as COD duration increased only if the number of changeovers did not decrease and the rate of responding during the COD remained uniformly high.

Figure 3 shows that, under the FRCO, there were typically only a few responses on the lean schedule prior to the changeover, presumably because the majority of reinforcers on this schedule were available for the first postchangeover response. These shorter run lengths on the lean schedule drive response ratios under the FRCO toward overmatching. This analysis is not meant to imply, however, that all values of the FRCO will produce overmatching. Pliskoff and Fetterman (1981) found that a changeover requirement of FR 1 produced undermatching, whereas a requirement of FR 4 produced overmatching. Decreasing the ratio requirement increases the number of changeovers (Pliskoff \& Fetterman, 1981), thereby decreasing run length and bout time, with greater reductions on the rich schedule, since both are already relatively short on the lean schedule. Such a change produces a shift in molar measures from overmatching toward matching or undermatching.

In addition to predicting that response ratios should undermatch reinforcer ratios with a COD and overmatch with an FRCO, Dreyfus et al. (1982) predicted that there should be smaller differences in time allocation under these two changeover requirements. The present results confirm the predictions that response allocation under the COD and FRCO would differ at both the molar and the molecular level and the prediction that time allocation would not differ.

Although this analysis and supporting data demonstrate that molecular relations between behavior and its consequences affect the molar outcome, they do not support the conclusion that concurrent schedule performance is determined completely by molecular contingencies-that is, that molecular relations are fundamental and that molar relations are derived. There are several problems with such a conclusion. First, insensitivity of behavior to local contingencies has been demonstrated in several experiments (Nevin, 1969; Williams, 1985). Second, there are ways other than those described above to produce undermatching and overmatching-for example, alternating responses to schedules that provide unequal rates of reinforcement produces undermatching. Third, changeover requirements do not completely explain performance in the present situation-they do not explain why performance approximates matching in the first place. Finally, although the run length and reinforced run length data suggest that reinforcement acts locally to produce the observed patterns, which is a molecular effect, this effect is manifested by its repeated occurrence over time, which is a molar effect. The present results are compatible with the conclusion that performance on concurrent schedules is determined by both molar and molecular relations between behavior and its consequences. The regularities in the local patterns of performance engendered by the different changeover requirements do not account for the matching relation, but they can plausibly account for deviations from matching that occur in these circumstances.

Nevin (1982) has suggested that molar and molecular approaches to the study of behavior are indeed more complementary than has been implied by the exclusionary rhetoric. And there are other data to support the conclusion that choice behavior is controlled by both molecular and molar relations between behavior and its consequences. For example, Stubbs, Fetterman, and Dreyfus (1987) showed that differential reinforcement of sequences of responses caused the creation of response units, which is a result of molecular control, but that the frequency with which these response units were emitted depended on the relative reinforcement rate for each sequence, which is a molar phenomenon. In another example, Williams (1991) trained rats on a probability learning task in which the local contingencies of reinforcement (i.e., the probability of reinforcement for an alternative, given the outcome of the prior trial) exerted more control with shorter 
intertrial intervals. With longer intertrial intervals, choices were controlled by the relative rate of reinforcement for each response. In these situations, and in the present experiment, regularities between behavior and its consequences at both the molar and the molecular level determined behavioral output. In different situations, molar or molecular contingencies may exert more control. The challenge is to develop theories that can accommodate controlling variables at both levels.

\section{The Matching Law: What's in a Norm?}

The success of the matching law as a description of choice behavior has raised concerns about its theoretical status. For example, Timberlake (1982) has expressed concern that unless the parameters of the generalized matching equation can be shown to be related "systematically to measurable independent variables, they function primarily as free parameters to increase the accuracy of fit to data" (p. 550). Whereas research has shown that $a$ varies with a number of variables, including, but not limited to, the absolute reinforcement rate, amount of training, and discriminability of the alternatives (see Davison, 1991b; Davison \& McCarthy, 1988, for reviews), it is not clear that the variation in $a$ produced by these various manipulations is amenable to a single theoretical interpretation of this parameter. One approach to dealing with the concern expressed by Timberlake has been to assume that the parameter $a$ of the generalized matching equation is invariant. Current interest in determining the "general outcome" on concurrent schedules is driven, in part, by this consideration. Several authors (Baum, 1979; Myers \& Myers, 1977; Wearden \& Burgess, 1982) have undertaken reviews aimed at characterizing in terms of the matching law normative performance on concurrent schedules-is it matching, undermatching? These authors have generally concluded that undermatching rather than matching is the norm. It has been standard practice in these reviews, however, to include studies in which COD has been used and to exclude procedures, like the FRCO, that produce overmatching.

Taylor and Davison (1983) have addressed differences in molar results produced by COD and FRCO requirements, arguing that overmatching with an FRCO results from the exclusion of changeover ratio responses from computation of response ratios (see also Williams, 1988). These authors show, for one set of data, that including FRCO responses produces undermatching rather than overmatching. There is some merit to the argument that a fair comparison between the COD and FRCO would include changeover responses under each. For example, Figure 5 shows that there are similarities in the behavior generated by COD and FRCO requirements. Differences in performance within and between rows notwithstanding, the most striking result of comparing the panels on the top with those on the bottom is that responding under both procedures is characterized by a high-rate component during the COD or changeover ratio, and a low-rate component after the COD has elapsed or after completion of the changeover ratio. These similarities seem compatible with the argument that molar differences in performance under the COD and FRCO result from a failure to include changeover-ratio responses in response ratios. On the other hand, one might argue that, rather than including changeover-ratio responses in behavior ratios, there is greater justification for excluding responses and time during the COD (Baum, 1982). Silberberg and Fantino (1970) found that removing COD responses led to response ratios overmatching reinforcement ratios.

The present data were adjusted in both ways: COD time and responses were removed from the session totals, and FRCO responses and the time to complete the ratio were added to the session totals. With the use of these new session totals, response, time, and reinforcer ratios were computed and the generalized matching equation (2) was fit to the data. Figure 6 compares the slopes of the bestfitting lines before and after the adjustments to totals under the COD and FRCO components. These data were combined without regard for which changeover requirement occurred in the first component of the session. Prior to the adjustment, response ratios under the FRCO overmatch reinforcer ratios, and response ratios under the COD undermatch reinforcer ratios. Unadjusted time ratios are closer to matching under both changeover requirements. After the adjustment, response and time ratios under the COD overmatch reinforcer ratios and response and time ratios under the FRCO undermatch reinforcer ratios.

Thus, including changeover-ratio responses and time to complete the changeover ratio in response and time totals under an FRCO produces results similar to those with the COD, undermatching. On the other hand, excluding responses and time during the COD from response and

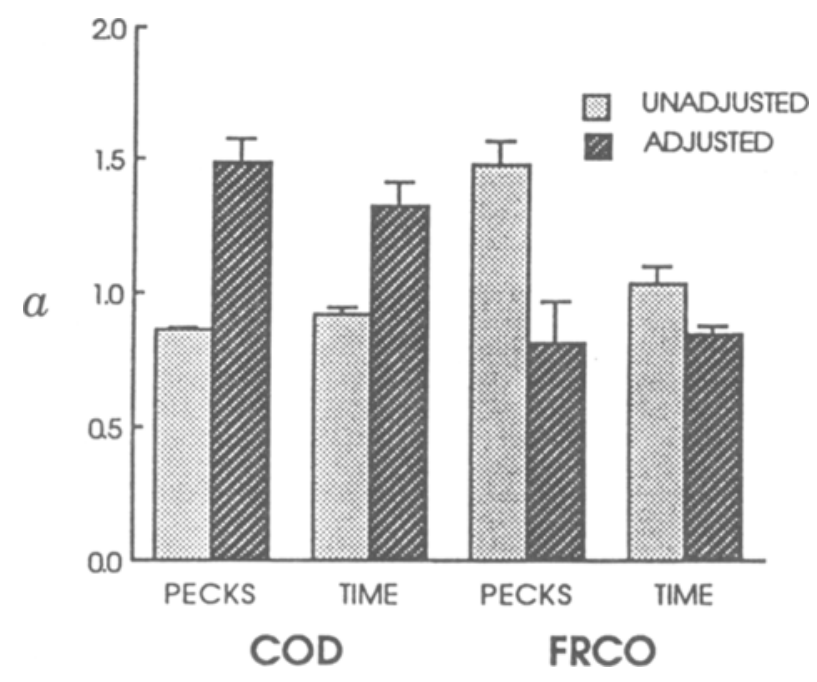

Figure 6. Adjusted and unadjusted slopes of the generalized matching equation. Adjustments involved subtracting pecks and time during the COD from totals or adding pecks and time during the FRCO to the totals. (The best-fitting lines were computed for each pigeon and slopes were averaged over pigeons. Bars represent standard errors of the means.) 
time totals produces results similar to those with the FRCO, overmatching. We would appear, then, to be able to have either undermatching or overmatching as the norm. The question then becomes, which is more appropriate-adding FRCO responses and time or subtracting COD responses and time?

If we conclude that changeover ratio responses should be included and that undermatching is therefore the "general" result, what are we to make of experiments like that of Baum (1982), in which the changeover response entailed traveling around a barrier? Baum found that with the most stringent travel requirement, response and time ratios overmatched reinforcer ratios. Because the changeover requirement, traversing a barrier, was qualitatively different from the reinforced response, keypecking, there is no convenient or obvious way to add the changeover responses to the keypecks. In spite of its greater ecological validity, we might conclude that this procedure is an oddity and therefore does not seriously challenge a conclusion about the "general outcome" on concurrent schedules. Baum points out, however, that requiring travel as the changeover response is one of a class of procedures that are similar in several important respects. These procedures include requiring a number of responses for changeover (i.e., an FRCO; Pliskoff et al., 1978), scheduling a changeover-produced electric shock (Todorov, 1971) or a changeover-produced blackout (Boelens, Kop, \& Slangen, 1989; Silberberg \& Fantino, 1970), and Baum's travel requirement. In addition, Davison (1991a) has reported results from a procedure in which completion of a fixed interval was required for changing main-key schedules. Each of these procedures involves some cost in changing schedules, and, in this respect, they are similar to a COD requirement. They are also similar in that each allows reinforcement of the first postchangeover mainkey response. Finally, they are similar in that overmatching of response ratios to reinforcer ratios is a common result under each. Whereas these changeover procedures are similar to a COD in the first respect, they differ from a COD in the eligibility for reinforcement of the first postchangeover main-key response and in the molar results that they produce.

The aforementioned reviews were correct in identifying undermatching as the most frequent result of concurrent schedule performance; but this situation has arisen only insofar as the most common technique for separating choices of the schedules is a COD in the duration range likely to produce undermatching (coupled, perhaps, with the use of arithmetic VI schedules; see Taylor \& Davison, 1983). If the changeover ratio, travel, or any of the procedures mentioned above was the most common, overmatching might be the norm. Clinging to the view that undermatching or any other single "general outcome" characterizes concurrent schedule performance requires either ignoring a substantial body of literature or tinkering with the data. Another possible resolution, though, is to reject the assumption that there must be a "general outcome" and to seek to understand the origins of different outcomes. Theoretical consequences of rejecting this assumption notwithstanding, a consideration of the local contingencies created by the different changeover requirements provides one such avenue of understanding.

The claim is not that changeover requirements are singularly important in understanding choice behavior-that is, that they alone will permit an accurate prediction of the outcome of a choice situation. For example, it is widely held that failure to separate schedules of a concurrent pair with a COD or some other changeover requirement will result in undermatching, yet acceptable matching can occur when only a single peck is required for changing schedules and the first postchangeover response is eligible for reinforcement (Heyman, 1979; Stubbs \& Pliskoff, 1969). The contingencies created by different changeover requirements, the effects of the contingencies, and the ways in which the effects interact with the effects of other relevant variables (e.g., absolute rate of reinforcement, amount of training) are very complex. The present data make it clear, though, that the deviations from "perfect matching" that accompany a COD and an FRCO can be understood as resulting from local contingencies created by those changeover requirements.

\section{Summary and Conclusions}

Scheduling a COD or an FRCO in different portions of a session produced molar and molecular differences in concurrent schedule performance. The molecular details of that performance can be understood as a result of the local availability of reinforcers on concurrent schedules and the contingencies created by the different changeover requirements. The molar differences in performance under the COD and FRCO can be understood, in turn, as resulting from the local patterns of behavior. Insofar as these molar differences in performance cannot be attributed to differences in molar controlling variables, the current experiment demonstrates one situation in which molecular processes modulate control by molar variables. These findings challenge the related assumptions that there is a "general outcome" on concurrent schedules and that performance on concurrent schedules can be understood completely in terms of molar variables. By overemphasizing the role of molar variables in the control of choice behavior, these assumptions minimize the role of molecular variables, exaggerate our understanding of the processes underlying choice, and, ultimately, may impede progress toward that understanding.

\section{REFERENCES}

BAUM, W. M. (1974). On two types of deviation from the matching law: Bias and undermatching. Journal of the Experimental Analysis of Behavior, 22, 231-242.

BAUM, W. M. (1979). Matching, undermatching, and overmatching in studies of choice. Journal of the Experimental Analysis of Behavior, 32, 269-281.

BAUM, W. M. (1982). Choice, changeover, and travel. Journal of the Experimental Analysis of Behavior, 38, 35-49.

Boelens, H., KoP, P. P. M., \& Slangen, J. (1989). Concurrent schedules: Effects of blackout during the changeover delay. Behavioural Processes, 18, 87-97. 
CAtania, A. C., Reynolds, G. S. (1968). A quantitative analysis of the responding maintained by interval schedules of reinforcement. Journal of the Experimental Analysis of Behavior, 11, 327-383.

Commons, M. L., Herrnstein, R. J., \& Rachlin, H. C. (Eds.) (1982). Quantitative analyses of behavior: Vol. 2. Matching and maximizing accounts. Cambridge, MA: Ballinger.

DAvison, M. [C.] (199la). Choice, changeover, and travel: A quantitative model. Journal of the Experimental Analysis of Behavior, 55, 47-61.

DAvison, M. [C.] (1991b). Stimulus discriminability, contingency discriminability, and complex stimulus control. In M. L. Commons, J. A. Nevin, \& M. C. Davison (Eds.), Signal detection: Mechanisms, models, and applications (pp. 57-78). Hillsdale, NJ: Erlbaum.

Davison, M. C., McCARTHY, D. (1988). The matching law: A research review. Hillsdale, NJ: Erlbaum.

Dreyfus, L. R., Dorman, L. G., Fetterman, J. G., \&tubes, D. A (1982). An invariant relation between changing over and reinforcement. Journal of the Experimental Analysis of Behavior, 38, 327-338.

DUNN, R. M. (1982). Choice, relative reinforcer duration, and the changeover ratio. Journal of the Experimental Analysis of Behavior, 38, 313-319.

He yman, G. M. (1979). A Markov model description of changeover probabilities on concurrent variable-interval schedules. Journal of the Experimental Analysis of Behavior, 31, 41-51.

MENLOVE, R. L. (1975). Local patterns of responding maintained by concurrent and multiple schedules. Journal of the Experimental Analysis of Behavior, 23, 309-337.

MYERS, D. L., \& MYERS, L. E. (1977). Undermatching: A reappraisal of performance on concurrent variable-interval schedules of reinforcement. Journal of the Experimental Analysis of Behavior, 27, 203-214.

NeviN, J. A. (1969). Interval reinforcement of choice behavior in discrete trials. Joumal of the Experimental Analysis of Behavior, 12, 875-885.

Nevin, J. A. (1982). Some persistent issues in the study of matching and maximizing. In M. L. Commons, R. J. Herrnstein, \& H. Rachlin (Eds.), Quantitative analyses of behavior: Vol. 2. Matching and maximizing accounts (pp. 153-165). Cambridge, MA: Ballinger.

Puskofr, S. S. (1971). Effects of symmetrical and asymmetrical changeover delays on concurrent performances. Journal of the Experimental Analysis of Behavior, 16, 249-256.

Pliskoff, S. S., Cicerone, R., \& Nelson, T. D. (1978). Local response-rate constancy on concurrent variable-interval schedules of reinforcement. Journal of the Experimental Analysis of Behavior, 29, 431-446.

Puskoff, S. S., \& Dreyfus, L. R. (1982, April). Some features of mainkey response runs on concurrent variable-interval schedules of reinforcement. Paper presented at the meeting of the Eastern Psychological Association, Baltimore.
Pliskoff, S. S , \& Fetterman, J. G. (1981). Undermatching and overmatching: The fixed-ratio changeover requirement. Journal of the Experimental Analysis of Behavior, 36, 21-27.

SHImp, C. (1982). Reinforcement and the local organization of behavior. In M. L. Commons, R. J. Herrnstein, \& H. Rachlin (Eds.), Quantitative analyses of behavior: Vol. 2. Matching and maximizing accounts (pp. 111-130). Cambridge, MA: Ballinger.

Silberberg, A., \& Fantino, E. (1970). Choice, rate of reinforcement, and the changeover delay. Journal of the Experimental Analysis of Behavior, 13, 187-197.

SilberberG, A., Ziriax, J. M. (1982). The interchangeover time as a molecular dependent variable in concurrent schedules. In $M$. L. Commons, R. J. Hermstein, \& H. Rachlin (Eds.), Quantitative analyses of behavior: Vol. 2. Matching and maximizing accounts (pp. 131151). Cambridge, MA: Ballinger.

Stubbs, D. A., Fetterman, J. G., \& Dreyfus, L. R. (1987). Concurrent reinforcement of response sequences. In M. L. Commons, J. E. Mazur, J. A. Nevin, \& H. Rachlin (Eds.), Quantitative analyses of behavior: Vol. 5. The effects of delay and intervening events on reinforcement value (pp. 205-224). Hillsdale, NJ: Erlbaum.

StubBs, D. A., \& Pliskoff, S. S. (1969). Concurrent responding with fixed relative rate of reinforcement. Journal of the Experimental Analysis of Behavior, 12, 887-895.

TAYloR, R., \& DAvison, M. [C.] (1983). Sensitivity to reinforcement in concurrent arithmetic and exponential schedules. Journal of the Experimental Analysis of Behavior, 39, 191-198.

Timberlake, W. (1982). The emperor's clothes: Assumptions of the matching theory. In M. L. Commons, R. J. Herrnstein, \& H. Rachlin (Eds.), Quantitative analyses of behavior: Vol. 2. Matching and maximizing accounts (pp. 549-568). Cambridge, MA: Ballinger.

Todorov, J. C. (1971). Concurrent performances: Effect of punishment contingent on the switching response. Journal of the Experimental Analysis of Behavior, 16, 51-62.

WeArden, J. H., \& Burgess, I. S. (1982). Matching since Baum (1979). Journal of the Experimental Analysis of Behavior, 38, 339-348.

Williams, B. A. (1985). Choice behavior in a discrete-trial concurrent VI-VR: A test of maximizing theories of matching. Learning \& Motivation, 16, 423-443.

WILlJams, B. A. (1988). Reinforcement, choice, and response strength. In R. C. Atkinson, R. J. Hermstein, G. Lindzey, \& R. D. Luce (Eds.), Stevens's Handbook of experimental psychology, 2nd ed.: Vol. 2. Learning and cognition (pp. 167-244). New York: Wiley. Williams, B. A. (1991). Choice as a function of local versus molar reinforcement contingencies. Joumal of the Experimental Analysis of Behavior, 56, 455-473.

(Manuscript received March 10, 1992; revision accepted for publication January 21,1993 .) 